\title{
B-Mode and Doppler Ocular Ultrasound Evaluation in Healthy and Positive Dogs for Visceral Canine Leishmaniasis
}

\author{
Elzivânia Gomes da Silva', Renan Paraguassu de Sá Rodrigues², Gerson Tavares Pessoa', \\ Andrezza Braga Soares da Silva², Laecio da Silva Moura', Francisco das Chagas Araújo Sousa ${ }^{3}$, \\ Kassio Vieira Macedo ${ }^{4}$ \& Flávio Ribeiro Alves ${ }^{5}$
}

\begin{abstract}
Background: The use of ultrasound examination in the evaluation of ophthalmopathies has been gaining more and more space within the ophthalmologic clinical routine. The hemodynamic study of ocular vascularization may anticipate future changes, aiding in the adequate establishment of therapeutic conduits. The objective of this study was to evaluate the structures of the ocular bulb and to perform the hemodynamic evaluation of the flow of the external ophthalmic artery of dogs with canine visceral leishmaniasis (CVL) correlating with healthy animals.

Materials, Methods \& Results: For this purpose, 100 animals were used, of these 70 positive for CVL and 30 healthy animals, submitted to B-mode and Doppler ultrasound examination. Two-dimensional evaluation included identification of ocular changes and biometry of the following segments: axial length (M1), anterior chamber depth (M2), lens thickness (M3), lens length (M4), glass chamber depth (M5), optical disc length (M6) and optic nerve length (M7). The Doppler velocimetric evaluation included the identification and hemodynamic evaluation of the external ophthalmic artery, being measured: systolic peak velocity (SPV), final diastolic velocity (FDV), resistivity index (RI) and pulsatility index (PI). Ophthalmopathies were frequent in animals with leishmaniasis in both right (91.42\%) and left (29.14\%) eyes, with identification of capsular cataract, lens dislocation, retinal detachment and lens rupture. No significant statistical difference $(P>0.05)$ was observed when comparing the biometric values between the right and left eyes of the animals with CVL, as well as for the measurements between healthy and CVL animals. Hemodynamic indexes of the flow of the external ophthalmic artery presented narrow limits for the right and left eyes of the positive animals, not statistically different from each other. However, a significant difference was observed when compared to hemodynamic evaluations of the flow of the ophthalmic artery between the right eyes of the group of normal animals and that of the carriers of leishmaniasis, with the latter presenting values superior to the first one. The B-mode and Doppler ultrasonographic evaluation enabled the morphological characterization of the ocular bulb, the identification of ophthalmopathies and the hemodynamic evaluation of the external ophthalmic artery of dogs with canine visceral leishmaniasis, establishing values that could be used in clinical ophthalmologic routine.

Discussion: The presence of ocular changes diagnosed by B-mode ultrasonography were common in dogs with canine visceral leishmaniasis. Ocular lesions were observed in $80.5 \%$ of dogs with leishmaniasis, presenting a high frequency, corroborating with the results in the present research. In $22 \%$ of the animals, B-mode ultrasonographic lesions were identified in both eyes, 64 of these presented changes only in the right eye and 16 in the left eye. Ophthalmopathies can be uni or bilateral and cause more than one alteration in the same eye, resulting from both the immune-mediated mechanisms caused by the agent and direct parasitism. Although the literature reports that the highest frequency of lesions is bilateral, only 16 animals had alterations in both eyes. The origin of ophthalmopathies may be related to the species and tropism of the parasite, type and duration of the immune response developed by the host. The greater frequency of bilateral ophthalmopathies can have correlation with the systemic disease, in which in the initial stages of the disease only one eye is affected and the occurrence of bilateral manifestations is related to the chronic cases.
\end{abstract}

Keywords: Biometry, ocular bulb, Doppler velocimetry, hemodynamics, ophthalmology.

DOI: $10.22456 / 1679-9216.107665$

Received: 24 May 2020

Accepted: 10 September 2020

Published: 27 September 2020

${ }^{1}$ Animal Science Post-Graduate Program; ${ }^{2}$ Post-Graduate Program in Technologies Applied to Animals of Regional Interest; ${ }^{4}$ Health Science PostGraduate Program \& ${ }^{5}$ Department of Veterinary Morphophysiology, Federal University of Piauí (UFPI), Teresina, PI, Brazil. ${ }^{3}$ Department of Medicine, Faculty of Medical Science, State University of Piauí, (UESPI), Teresina. CORRESPONDENCE: F.R. Alves [flavioribeiro@ufpi.edu.br]. Department of Veterinary Morphophysiology - UFPI. CEP 64049-550 Teresina, PI, Brazil. 


\section{INTRODUCTION}

Canine visceral leishmaniasis (CVL) is a disease caused by protozoa of the genus Leishmania sp. [31] and transmitted by the dipterous Lutzomya longipalpis [23]. In Brazil it is also known as calazar, being caused by L. chagasi [11]. The Canis familiaris is considered to be an important source of infection because it is the main urban reservoir for the vector in the environment and because it is generally associated with the occurrence of cases in humans $[1,27]$.

The most common clinical signs in dogs with CVL are dermatopathies. The animals may also develop apathy, splenomegaly, lymphadenomegaly, onychogrifose, emaciation, anemia [6,11], renal and hepatic disease [29].

Several ocular clinical signs are related to pathology. Karyatoconjunctivitis and blepharitis are among the most frequent, although there is also the prevalence of granulomatous or lymphocytic uveitis, associated with corneal edema and synechiae $[14,29]$. The ophthalmopathies may or may not be associated with systemic signs, most of which are bilateral [13].

B-mode ocular ultrasonography is an important diagnostic tool used in the evaluation of retrobulbar and periorbital diseases, assisting both localization and characterization of lesions $[21,34]$.

Due to the association of canine visceral leishmaniasis with the development of ophthalmopathies, the aim of this study was to perform the B-mode ultrasound evaluation of the ocular structures and the Doppler ultrasound study of the flow of the external ophthalmic artery of normal dogs and individuals with canine visceral leishmaniasis, correlating both groups.

\section{MATERIALS AND METHODS}

\section{Experimental design}

We examined 100 dogs, totaling 200 ocular bulbs, ranging in age from one to fourteen years old. The animals were separated into two groups: 70 dogs (4 pinschers, 4 daschunds, 20 poodles and 42 hybrids) with positive serology and parasitological examination for CVL, presenting or not ocular lesions at clinical examination, were the group of animals with the disease; and 30 dogs (3 Daschunds, 4 Pinschers, 13 Poodles and 10 hybrids), free of ocular and systemic alteration at the clinical examination, with serological and parasi- tological examination negative for CVL, formed the control group. All the animals came from the medical clinic service of the Veterinary University Hospital of the Federal University of Piauí (HVU/UFPI)

\section{B-mode ultrasound evaluation}

Ultrasonographic evaluation of the optical components was performed using a portable ultrasound device (Z6-Vet) ${ }^{1}$, associated to the $8.5 \mathrm{MHz}$ microconverter transducer, calibrated at a sound velocity of $1,540 \mathrm{~m} \mathrm{~s}$. In order to minimize the variables that could interfere in the results, all the scans were performed by the same observer and the ultrasound device always calibrated in the same way regarding the positioning of the main focus and the intensity of brightness and contrast, in order to avoid the interobserver and interassay variations.

The animals were placed in sternum decubitus and contained manually. For the purposes of standardization, the right eye was first evaluated, and later the left eye was evaluated. A drop of anesthetic collyrium based on proximetacaine hydrochloride was instilled in both eyes to promote corneal desensitization, and then a layer of carboxymethylcellulose gel was applied onto the transducer that was positioned directly over the center of the cornea.

Scans were performed on the sagittal, transverse and dorsal planes, and the following measurements were performed in triplicate to minimize the experimental error: M1 - distance between the cornea and the internal face of the retinal-choroid-sclera complex (axial length); M2 - distance between the central point of the cornea and the center point of the anterior lens capsule (anterior chamber depth); M3 distance between the anterior and posterior capsule of the lens (lens thickness); M4 - distance between the lateral and medial poles of the lens (lens length); M5 - distance between the posterior lens capsule and the posterior bulb wall (depth of the vitreous chamber); M6 - optical disc length; M7 - length of the optic nerve (Figure 1-A).

\section{Doppler velocimetry}

A sagittal cut of the ocular globe was performed and after identification of the optic nerve the transducer was positioned about $2 \mathrm{~mm}$ from the posterior wall of the eye bulb and the external ophthalmic artery was identified by color Doppler. Shortly afterwards, the cursor was placed on this 
artery, with insonation angle $<60^{\circ}$, and the vascular flow measurement was performed by the spectral Doppler in the equipment itself. Three fluxometric evaluations were performed in each artery of both eyes in each animal, to guarantee the accuracy of the values obtained, with the flow measured in both systole and diastole. Resistivity and pulsatility indexes were obtained automatically by the device software after manual delineation of systolic peak velocity and final diastolic velocity (Figure 1-B).
After the end of the examinations, both eyes were cleaned with $0.9 \%$ sodium chloride solution in order to avoid possible irritation caused by the gel.

\section{Statistical analysis}

The data were submitted to the error normality test (Shapiro-Wilk and Kolmogorov-Smirnov test) and the means were then analyzed using the paired Student's t-test for the interpretation of the parameters, considering a confidence interval of $5 \%$.
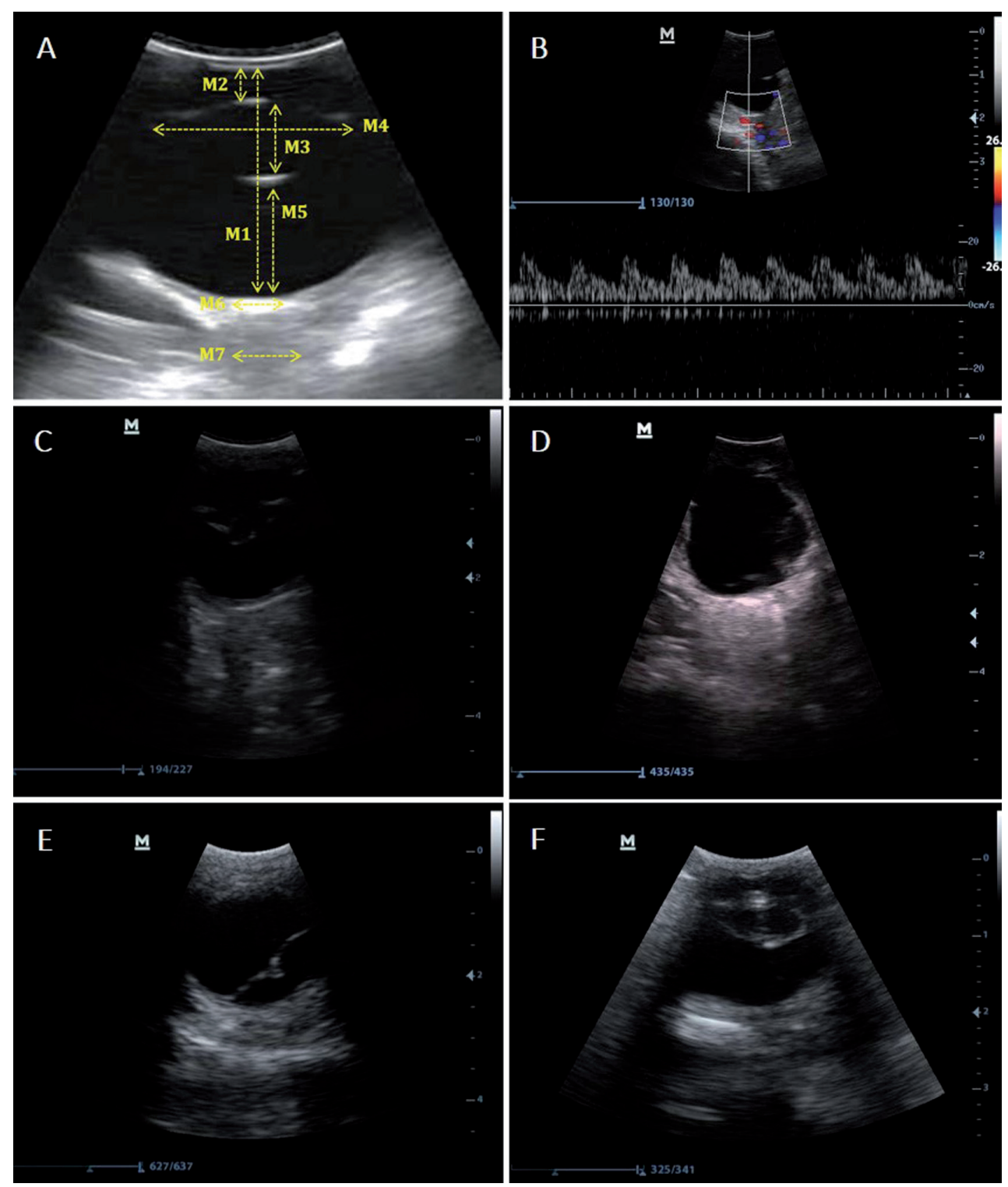

Figure 1. B-mode and Doppler images of ultrasound evaluation of healthy and with leishmaniasis dogs. A- Structures present in the normal ocular bulb and measurable follow-up in ophthalmic biometry. B- Flow pattern of the external ophthalmic artery. Note the presence of the dichrotic tracing. C- Lens rupture, with presence of rounded and anechoic formation on the posterior face of the lens. D- Dislocation of the lens, evidencing its presence in the vitreous region. E- Retinal detachment, marked by the "swallow wing" aspect. It is observed that the retina remains attached to the optic nerve and the ora serrata (regmatogenic detachment). F- Incipient capsular cataract, with presence of increased echogenicity on the anterior and posterior face of the lens. 


\section{RESULTS}

Through B-mode ultrasound examination it was possible to perform the identification and evaluation of all the structures that make up the ocular bulb, besides the characterization of the present ocular alterations. The ophthalmic pathologies found by the two-dimensional mode in CVL positive animals, in ascending order were: lens rupture, lens dislocation, retinal detachment and cataract. Lens rupture was observed only in the right eye of two animals (2.86\%) and lens dislocation, only in the left eye of five animals (7.14\%). Retinal detachment and cataract were simultaneously identified in both eyes of seven (10\%) and nine (12\%) animals, respectively (Table 1).

Ultrasonographic changes were more frequently identified in the right eye (91.42\% - 64 animals) when compared to the left one (29.14\% - 21 animals), so that all animals that presented retinal displacement and cataract in the left eye presented in the contralateral eye, but the opposite was not observed. Of the 70 animals with CVL, 64 presented some ophthalmopathy in at least one eye, so that in 16 animals, eye lesions were identified in both eyes. In 49 animals, no alteration was observed in the left eye, and only 6 dogs showed no lesions identified by ultrasonographic examination in the right eye.

The lens rupture was characterized by the presence of irregularity in the posterior face, with visible rounded formation suggesting cicatricial tissue, and an increase in echogenicity (opacity) was also observed throughout its length. It was also observed presence of punctate echoes (cellularity) in the vitreous humor, suggesting signs of hemorrhage (Figure 1-B).

When the animals that presented dislocation of the lens were identified, in $100 \%$ of the dogs the dislocation was of the posterior type. Complete displacement of the lens to the side of the bulb was observed, with rupture of the zonular ligaments, being visible in topography of the vitreous chamber, being observed an increase of its echogenicity in all affected animals. In one of the animals it was possible to identify the presence of a fine echogenic filament, representing posterior vitreous displacement (Figure 1-C).

Regarding retinal detachment, in $10 \%$ of dogs, this alteration was identified in both eyes and in $15.71 \%$ in the right eye. Retinal membranes were visualized with total displacements and non-regmatogenic type, remaining adhered posteriorly to the optic nerve head and, previously to the ora serrata, with a wavy aspect (Figure 1-D).

Cataract was the most frequently identified ophthalmopathy in animals with canine visceral leishmaniasis, characterized by an increase in echogenicity of the anterior and posterior faces of the lens along its entire length (Figure 1-E).

In relation to the CVL negative animals, all structures present in the ocular bulb presented normality patterns for the species. The anterior chamber was identified as an anechoic structure by the presence of the aqueous humor, located between the cornea and the anterior face of the lens. The iris and ciliary body were visualized together in the peripheral-equatorial region of the lens as a unique structure in the sagittal section, triangular and echogenic. Later, the lens, also known as crystalline, was internally occupied by anechoic content, characterized as a biconvex structure, formed by an anterior and posterior echogenic face. The vitreous space, a component completely filled with anechoic content (vitreous humor), was visible between the posterior face of the lens and the posterior wall of the ocular bulb. The optic disc, identified in the posterior wall of the ocular bulb, was hyperechogenic to it. And the last structure observed, the optic nerve, was ultrasonographically funnel shaped, hypoechogenic in relation to the adjacent retrobulbar tissue, located caudal to the optic disc.

Biometric measurements of the optical components of animals with canine visceral leishmaniasis were performed in anteroposterior horizontal cut and are present in Table 2. Although $91.42 \%$ of the animals presented ophthalmic alteration in at least one eye, no significant statistical difference was observed $(P$ $>0.05$ ) between right and left eyes for M1, M2, M3, M4, M5, M6 and M7 measurements. The thickness of the lens (M3) was the biometric variable that showed the greatest variation, from 0.66 to $0.74 \mathrm{~cm}$ in the right eye, and 0.82 to $0.92 \mathrm{~cm}$ in the left; while the length of the optical disc (M6) obtained a smaller variation in size, with a mean of $0.40 \pm 0.05 \mathrm{~cm}$ for the right eye and $0.39 \pm 0.06 \mathrm{~cm}$ for the left one.

When comparing the biometric values of ocular structures between normal and CVL animals, there was no statistically significant difference $(P>0.05)$ when compared within the same group (normal animals and animals with leishmaniasis). A tendency to increase the size of the ocular components in positive animals 
was observed, with the exception of the lens thickness (M3) in the right eye and the length of the optic nerve (M7) on the left. However, this increase was considered discrete, not representing a difference between the groups studied (Table 3).

The Doppler tool allowed identification of the external ophthalmic artery in all the animals studied. In both normal and positive animals, the flow was characterized as a parabolic laminar of intermediate resistivity with high systolic peak and dichrotic tracing (Figure 1-B).

According to the data presented in Table 4, no significant statistical difference $(P>0.05)$ was observed in relation to hemodynamic indices of the ophthalmic artery between the right and left eyes of the animals with leishmaniasis. The mean resistivity index (RI) ranged from 0.65 to 0.67 , presenting a mean basal velocity of $19.45 \mathrm{~cm} / \mathrm{s}$ at the systolic peak and $6.40 \mathrm{~cm} / \mathrm{s}$ at the end of the diastole for the right eye and at the velocity mean baseline of $18.94 \mathrm{~cm} / \mathrm{s}$ at the systolic peak and $6.60 \mathrm{~cm} / \mathrm{s}$ at the end of the diastole.

When Doppler velocimetric indices were compared between the two groups of animals (normal $\mathrm{x}$ positive), taking into account the same eye, it was verified that there was no significant statistical difference $(P>0.05)$ between left eyes of healthy animals and with leishmaniasis. However, when comparing the hemodynamic values for the right and left eye of normal and positive animals, it was possible to observe a statistically significant difference $(P<0.05)$ for all analyzed variables (RI, PI, SPV and FDV) an increase in all hemodynamic indices of animals with leishmaniasis in relation to normal animals (Table 5).

There was a positive correlation between the age of the animals with leishmaniasis and the biometric values, as observed in Table 6. Strong and positive dependence was observed in the right eye for the M1 and M7 values, reasonable for M2, M3, M5 and M6 and insignificant for M4. On the other hand, for the left eye, strong dependence was observed for M1 and M3, reasonable for M2 and M7, weak for M5 and M6 and insignificant for M4 (Table 6).

Likewise, the systolic peak velocity (SPV) and the resistivity index (RI) in the right and left ocular hemodynamic measurements of the animals with leishmaniasis showed a positive correlation with age, being considered strong between the RI and the age when taken in the right eye and, reasonable for the other associations (Table 7).

When the correlation between the SPV and the RI of the right and left eyes within the same group of animals was verified, there was a strong and positive correlation in all the associations, with $r=0.93$ and 0.91 for the right and left eyes of the normal animals, respectively, and $r=0.96$ for the right eye and $r=0.98$ for the left, in animals with leishmaniasis.

There were no statistical differences between males and females $(P>0.05)$ and biometric and hemodynamics variables within each group (normal dogs and dogs positive for CVL). Likewise, there was no positive correlation between weight and biometric and hemodynamic variables in both groups.

Table 1. Morphological alterations evidenced to B-mode ocular ultrasound examination of positive animals for Canine Visceral Leishmaniasis, Teresina, Piauí, Brazil, 2016.

\begin{tabular}{cccc}
\hline & Right eye & Left eye & \multicolumn{2}{c}{ Both eyes } \\
Ultrasonographic findings & $(\%)$ & $(\%)$ & $1 \%)$ \\
\hline Cataract & 62.85 & 12.00 & 12.00 \\
Retinal detachment & 25.71 & 10.00 & - \\
Lens dislocation & - & 7.14 & - \\
Lens rupture & 2.86 & - & - \\
\hline
\end{tabular}

Table 2. Mean and standard deviation $(\mathrm{cm})$ of the biometry of right and left ocular components of dogs with Canine Visceral Leishmaniasis, Teresina, Piauí, Brazil, 2016.

\begin{tabular}{ccc}
\hline Measures & Right eye & Left eye \\
\hline M1 & $1.86 \pm 0.07^{\mathrm{a}}$ & $1,80 \pm 0.09^{\mathrm{a}}$ \\
M2 & $0.25 \pm 0.07^{\mathrm{a}}$ & $0.24 \pm 0.09^{\mathrm{a}}$ \\
M3 & $0.70 \pm 0.04^{\mathrm{a}}$ & $0.87 \pm 0.05^{\mathrm{a}}$ \\
M4 & $1.26 \pm 0.10^{\mathrm{a}}$ & $1.27 \pm 0.09^{\mathrm{a}}$ \\
M5 & $0.87 \pm 0.05^{\mathrm{a}}$ & $0.82 \pm 0.04^{\mathrm{a}}$ \\
M6 & $0.52 \pm 0,06^{\mathrm{a}}$ & $0.50 \pm 0.06^{\mathrm{a}}$ \\
M7 & $0.40 \pm 0.05^{\mathrm{a}}$ & $0.39 \pm 0.06^{\mathrm{a}}$ \\
\hline
\end{tabular}

aValues followed by equal letters on the same line did not differ statistically $(P>0.05)$. M1: axial length, M2: depth of the anterior chambre, M3: lens thickness, M4: lens length, M5: depth of the vitreous chambre, M6: optical disc length, M7: optic nerve length. 
Table 3. Biometric comparison between the means and standard deviation $(\mathrm{cm})$ of the right and left ocular components of normal and Canine Visceral Leishmaniasis dogs, Teresina, Piauí, Brazil, 2016.

\begin{tabular}{ccccc}
\hline Measures & $\begin{array}{c}\text { Right eye } \\
\text { (normal) }\end{array}$ & $\begin{array}{c}\text { Right eye } \\
\text { (positive) }\end{array}$ & $\begin{array}{c}\text { Left eye } \\
\text { (normal) }\end{array}$ & $\begin{array}{c}\text { Left eye } \\
\text { (positive) }\end{array}$ \\
\hline M1 & $1.75 \pm 0.10^{\mathrm{a}}$ & $1.86 \pm 0.07^{\mathrm{a}}$ & $1.73 \pm 0.11^{\mathrm{a}}$ & $1.80 \pm 0.09^{\mathrm{a}}$ \\
M2 & $0.20 \pm 0.05^{\mathrm{a}}$ & $0.25 \pm 0.07^{\mathrm{a}}$ & $0.19 \pm 0.06^{\mathrm{a}}$ & $0.24 \pm 0.09^{\mathrm{a}}$ \\
M3 & $0.72 \pm 0.05^{\mathrm{a}}$ & $0.70 \pm 0.04^{\mathrm{a}}$ & $0.73 \pm 0.04^{\mathrm{a}}$ & $0.87 \pm 0.05^{\mathrm{a}}$ \\
M4 & $1.22 \pm 0.10^{\mathrm{a}}$ & $1.26 \pm 0.10^{\mathrm{a}}$ & $1.22 \pm 0.11^{\mathrm{a}}$ & $1.27 \pm 0.09^{\mathrm{a}}$ \\
M5 & $0.83 \pm 0.04^{\mathrm{a}}$ & $0.87 \pm 0.05^{\mathrm{a}}$ & $0.82 \pm 0.04^{\mathrm{a}}$ & $0.82 \pm 0.04^{\mathrm{a}}$ \\
M6 & $0.42 \pm 0.08^{\mathrm{a}}$ & $0.52 \pm 0.06^{\mathrm{a}}$ & $0.40 \pm 0.08^{\mathrm{a}}$ & $0,50 \pm 0.06^{\mathrm{a}}$ \\
M7 & $0.39 \pm 0,02^{\mathrm{a}}$ & $0.40 \pm 0.05^{\mathrm{a}}$ & $0.40 \pm 0.08^{\mathrm{a}}$ & $0.39 \pm 0.06^{\mathrm{a}}$ \\
\hline
\end{tabular}

aalues followed by equal letters on the same line did not differ statistically $(P>0.05)$. M1: axial length, M2: depth of the anterior chambre, M3: lens thickness, M4: lens length, M5: depth of the vitreous chambre, M6: optical disc length, M7: optic nerve length.

Table 4. Mean values and standard deviations of the Doppler velocimetric indexes of the external ophthalmic artery of dogs with Canine Visceral Leishmaniasis, Teresina, Piauí, Brazil, 2016.

\begin{tabular}{ccc}
\hline Hemodynamic indexes & Right eye & Left eye \\
\hline RI & $0.67 \pm 0.01 \mathrm{a}$ & $0.65 \pm 0.02 \mathrm{a}$ \\
PI & $1.20 \pm 0.07 \mathrm{a}$ & $1.08 \pm 0.09 \mathrm{a}$ \\
SPV & $19.45 \pm 1.12 \mathrm{a}$ & $18.94 \pm 1.20 \mathrm{a}$ \\
FDV & $6.40 \pm 0.23 \mathrm{a}$ & $6.60 \pm 0.13 \mathrm{a}$ \\
\hline
\end{tabular}

$\bar{a}$ Values followed by equal letters on the same line did not differ statistically $(P>$ $0.05)$. RI: resistivity index, PI: pulsatility index, SPV: systolic peak velocity, FDV: final diastolic velocity.

Table 5. Comparison between Doppler velocimetric indexes of external ophthalmic artery flow between normal and Canine Visceral Leishmaniasis dogs, Teresina, Piauí, Brazil, 2016.

\begin{tabular}{ccccc}
\hline Hemodynamic indexes & $\begin{array}{c}\text { Right eye } \\
\text { (normal) }\end{array}$ & $\begin{array}{c}\text { Right eye } \\
\text { (positive) }\end{array}$ & $\begin{array}{c}\text { Left eye } \\
\text { (normal) }\end{array}$ & $\begin{array}{c}\text { Left eye } \\
\text { (positive) }\end{array}$ \\
\hline RI & $0.63 \pm 0.03^{\mathrm{a}}$ & $0.67 \pm 0.01^{\mathrm{b}}$ & $0.63 \pm 0.03^{\mathrm{a}}$ & $0.65 \pm 0.02^{\mathrm{a}}$ \\
PI & $1.04 \pm 0.05^{\mathrm{a}}$ & $1.20 \pm 0.07^{\mathrm{b}}$ & $1.05 \pm 0.07^{\mathrm{a}}$ & $1.08 \pm 0.09^{\mathrm{a}}$ \\
SPV & $17.50 \pm 1,07^{\mathrm{a}}$ & $19.45 \pm 1.12^{\mathrm{b}}$ & $18.18 \pm 1.22^{\mathrm{a}}$ & $18.94 \pm 1.20^{\mathrm{a}}$ \\
FDV & $6.21 \pm 0.87^{\mathrm{a}}$ & $6.40 \pm 0.23^{\mathrm{b}}$ & $6.68 \pm 0.27^{\mathrm{a}}$ & $6.60 \pm 0.13^{\mathrm{a}}$ \\
\hline
\end{tabular}

avalues followed by equal letters on the same line did not differ statistically $(P>0.05)$. RI: resistivity index, PI: pulsatility index, SPV: systolic peak velocity, FDV: final diastolic velocity.

Table 6. Correlation between age and biometric values measured by two-dimensional ultrasonography for the right and left eye of dogs positive for Canine Visceral Leishmaniasis, Teresina, Piauí, Brazil, 2016.

\begin{tabular}{ccc}
\hline Measures & $\begin{array}{c}\text { Right eye } \\
R \text { value } \\
(\text { age })\end{array}$ & $\begin{array}{c}\text { Left eye } \\
R \text { value } \\
\text { (age) }\end{array}$ \\
\hline M1 & 0.90 & 0.90 \\
M2 & 0.87 & 0.86 \\
M3 & 0.81 & 0.92 \\
M4 & 0.67 & 0.69 \\
M5 & 0.87 & 0.74 \\
M6 & 0.85 & 0.76 \\
M7 & 0,90 & 0,88 \\
\hline
\end{tabular}

M1: axial length, M2: depth of the anterior chambre, M3: lens thickness, M4: lens length, M5: depth of the vitreous chambre, M6: optical disc length, M7: optic nerve length. 
Table 7. Correlation between age and Doppler velocimetry indexes of the external ophthalmic artery of dogs positive for Canine Visceral Leishmaniasis, Teresina, Piauí, Brazil, 2016.

\begin{tabular}{ccc}
\hline Hemodynamic indexes & $\begin{array}{c}\text { Right eye } \\
R \text { value } \\
(\text { age })\end{array}$ & $\begin{array}{c}\text { Left eye } \\
R \text { value } \\
(\text { age })\end{array}$ \\
\hline SPV (cm/s) & 0.87 & 0.88 \\
RI & 0.96 & 0.87 \\
\hline
\end{tabular}

SPV: systolic peak velocity, RI: resistivity index.

\section{DISCUSSION}

The presence of ocular changes diagnosed by B-mode ultrasonography were common in dogs with canine visceral leishmaniasis, with $91.42 \%$ (64/70) of the dogs showing at least one unilateral ocular alteration. This study corresponds to the first report of the ultrasound description of the ocular bulb of dogs positive for leishmaniasis, with identification and two-dimensional description of ocular alterations, besides being pioneer in the hemodynamic evaluation of the flow of the ophthalmic artery of dogs naturally infected with CVL.

Brito et al. [3] clinically evaluating 25 dogs naturally infected with Leishmania chagasi found $76 \%$ of ocular lesions during ophthalmic examination. They observed that $73.7 \%$ of the animals presented only one type of alteration, whereas $26.3 \%$ showed more than one alteration for the same eye. Molleda et al. [24] observed ocular lesions in $80.5 \%$ of dogs with leishmaniasis, presenting a high frequency, corroborating with the results in the present research. Peña et al. [29] diagnosed by means of clinical evaluation ocular and periocular changes in $24.4 \%$ of the 430 cases of positive dogs, being below the values found by Molleda et al. [24], and may be related to the pathogenicity of Leishmania involved, stage of disease and immune response of the animal [3].

In $22 \%$ of the animals, B-mode ultrasonographic lesions were identified in both eyes, 64 of these presented changes only in the right eye and 16 in the left eye. Ophthalmopathies can be uni or bilateral and cause more than one alteration in the same eye, resulting from both the immune-mediated mechanisms caused by the agent and direct parasitismo $[3,29]$. Although the literature reports that the highest frequency of lesions is bilateral, only 16 animals had alterations in both eyes. This may be related to the different stages of the disease, where there is initially only one eye involvement and, with its course, bilateral change occurs $[19,24,29]$. The origin of ophthalmopathies may be related to the species and tropism of the parasite, type and duration of the immune response developed by the host [14]. The greater frequency of bilateral ophthalmopathies can have correlation with the systemic disease, in which in the initial stages of the disease only one eye is affected and the occurrence of bilateral manifestations is related to the chronic cases [3]. In some animals, ocular and periocular manifestations correspond to the first apparent alteration of the disease, although they may occur in conjunction with other systemic signs $[12,29]$ and may appear in a period ranging from 1 month to 7 years [35].

It was possible to identify and characterize by ultrasonography the following pathologies: lens rupture, lens dislocation, retinal detachment and cataract. Calabrese et al. [4] evaluated ocular changes in mice experimentally infected with Leishmania amazonensis and found that ocular lesions may be associated with the deposition of immunoglobulins in response to type III hypersensitivity stimulated by the presence of parasite antigens. This accumulation of immunocomplexes favors the appearance of ocular lesions. The presence of lymphoplasmacytic inflammatory infiltrate was described in some eye follow-ups [3,13,24,25]. According to studies performed by several authors, the highest prevalence of ophthalmopathies in leishmaniasis occurs in the anterior portion of the eyes [3,24].

The lens rupture was identified in the right eye of 2 animals, being characterized by the discontinuity and irregularity of the posterior face of the capsule, with presence of echogenic points in suspension, indicating presence of cellularity in the vitreous space. The vitreous under normal conditions is homogeneous and without echogenicity. The presence of echogenicity in the vitreous space may be related to hemorrhages, degenerative processes, inflammation or cellular organization. In the case of a finding secondary to lens rupture in the animals under study, it is believed that the presence of punctiform echoes in the vitreous may be related to hemorrhage [18].

The dislocation of the lens was the third lesion most frequently found, being observed in the left eye of 5 animals. It was identified rupture of the zonular fibers originated in the ciliary body, causing the displacement of the lens to the vitreous region. In all animals the dislocation was characterized as being of the posterior type. This ocular manifestation may be secondary to increased 
intraocular pressure or the presence of inflammatory processes in the peripheral-equatorial region of the lens, where the iris and ciliary body are located.

Retinal displacement was identified in the right eye of 11 animals and in 7 animals in the left eye. This alteration may occur at a focal point or throughout its amplitude, and may be associated with echogenic masses, be of congenital origin, inflammatory, traumatic or secondary to cataract [18]. The retracted retinas remained adhered to the optic nerve and the ora serrata, being of this form of the regmatogenic type. The retinal detachment of the retina is caused by the presence of a continuity solution in the sensorineural retina, originating from the vitreous cavity, into the subretinal space, causing a separation of this layer from the pigment epithelium [10]. Color Doppler was used to confirm the detachment, where vascularization was observed on echogenic red-colored lines (in the direction of the transducer), as differential diagnosis for echogenic masses or internal clots to the vitreous [36].

Cataract was the most frequent ocular manifestation among positive animals $(50.85 \%)$, affecting both eyes in $12 \%$ of dogs, characterized by the presence of opacification in the anterior and posterior capsule of the lens. The ophthalmic ultrasound examination is an effective diagnostic tool that allows the identification and graduation of canine cataract. According to the anatomical location, all the animals presented cataract of the capsular type, since the increase of the echogenicity was only identified in the region of the front and back face of the lens [7] and, in relation to the stage of development, the dogs presented incipient cataract, since the opacity did not exceed $15 \%$ of the lens, being slightly thickened, thus not occurring visual impairment [33].

According to Table 2, it was observed no significant statistical differences between the means of the intraocular structures in the biometric assessment of the ocular bulb of dogs with CVL using the B-mode ultrasonographic examination. Although A-mode (onedimensional) ultrasonography is the most suitable technique for biometric evaluation of the eye because of its accuracy, B-mode biometry has proved to be efficient [5], and no statistical differences were identified when compared mode A to B. Another factor to be taken into account was the achievement of all measures by single examiner, since, although the B-mode presents good repeatability both inter and intra-observer, when dealing with small structures measurement, significant differences can occur [2].

Three measurements of each component were performed to determine the biometric values, and at the end the mean was calculated, as was done [20]. The axial length (M1) ranged from 1.71 to $1.93 \mathrm{~cm}$. Gonçalves et al. [16] evaluating 60 ocular bulbs of normal animals found variation from 1.78 to $1.98 \mathrm{~cm}$, being very close to the values found in the study for animals with leishmaniasis.

The thickness of the lens presented a mean of $0.70 \pm 0.04 \mathrm{~cm}$ for the right eye and, $0.87 \pm 0.05 \mathrm{~cm}$ for the left one, being relatively larger in the left eye, although no difference was observed when comparing both. Gonçalves et al. [16] found values of $0.61 \pm$ $0.12 \mathrm{~cm}$, lower than the results of the present research, which can be explained by the homogeneity of the weight of the animals studied ( 5 to $12 \mathrm{~kg}$ ), while dogs with leishmaniasis presented weight ranging from 2.5 to $28.5 \mathrm{~kg}$. Similarly, Paunksnis et al. [28] evaluating 10 adult dogs weighing between 7 and $9.5 \mathrm{~kg}$ found values between 0.47 and $0.68 \mathrm{~cm}$.

The depth of the anterior chamber (M2) was quite similar when comparing both eyes. This homogeneity may be related to the fact that there is little variation of corneal aplanation by the probe due to the use of anesthetic collyrium before the examination [9]. Ekesten [9] evaluating mildly sedated and non-sedated Samoied dogs, observed large differences in anterior chamber depth in both groups, and were relatively large in sedated dogs. Miller \& Murphy [22] found that the depth of the anterior chamber was the variable most affected by the biometry errors due to the probe's corneal aplanation, leading to a decrease in its depth.

The depth of the vitreous chamber ranged from 0.78 to $0.92 \mathrm{~cm}$ between right and left eyes in dogs with CVL. Cottrill et al. [5] found that dogs weighing between 9 and $32 \mathrm{~kg}$ were equal to 0.81 to $0.95 \mathrm{~cm}$, compatible with the dogs of this study. Measurements of the length of the disc and of the optic nerve were also quite homogeneous when comparing both eyes.

According to Table 3, when comparing biometric values measured by B-mode in the evaluation of ocular structures between normal and positive dogs, there was no statistically significant difference $(P>0.05)$ between right and left eyes of although most of the animals with leishmaniasis presented different pathologies (Table 1), most did not cause significant changes in the 
internal anatomy of the eye that could hinder or prevent the measurement of optical components. Only in the animals that presented lens dislocation, the evaluations of the anterior chamber and the vitreous space were compromised. However, as the number of animals with this alteration was small (7.14\%) when compared to the total of dogs evaluated, and because this alteration was only identified in the left eye of 5 animals, no influence of the general evaluation of this group was evidenced of animals (positive for leishmaniasis).

Garcia-Alonso et al. [14] and Peña et al. [29] analyzed histologically the ocular structures of parasitized dogs and found the amastigote form of the parasite in the inflammatory infiltrate and macrophages in the ocular, sclera, cornea, limbus and ciliary bodies. The presence of the parasite in the intraocular tissue probably occurs due to the breakage of the blood barrier and the aqueous humor of the eye, allowing the passage of parasitized macrophages into the anterior chamber region [30].

Color Doppler allowed identification of the external ophthalmic artery of the retrobulbar region of all animals evaluated, as previously verified [15]. The blood flow from the external ophthalmic artery presented small variation between the right and left eyes in dogs with leishmaniasis (Table 4), with no statistically significant differences $(P>0.05)$. The small variations between the flows occurred due to the cardiac revolution, being influenced by the circulating blood volume, causing blood flow velocity to be higher during systole and lower in diastole [17].

The Doppler velocimetric parameters of the external ophthalmic artery flow of the normal and positive dog groups are shown in Table 5. Regarding the evaluation of the left eye, no significant statistical differences were evidenced, with blood flow maintaining narrow limits between the animals of both groups, with the resistivity index ranging from 0.60 to 0.66 for healthy animals and 0.63 to 0.67 for positive animals. In contrast, the arterial flow of the right eye of healthy animals was statistically different from that of animals with leishmaniasis, with all hemodynamic indexes (RI, PI, SPV and FDV) increased in relation to normal animals. This fact may be related to the percentage difference of alterations identified during the B-mode evaluation, since $91.42 \%$ of the animals had at least one lesion in the right eye, whereas only $29.14 \%$ presented lesions in the left eye, reflecting not only the occurrence of detectable two-dimensional lesions, but also a change in the hemodynamic profile of the ophthalmic artery flow.

Although the RI and PI of the ophthalmic artery flow of animals with leishmaniasis were increased in relation to healthy animals, both groups still showed values within normal for the species according to $[15,26]$. The use of the Doppler tool in the evaluation of blood flow parameters in ocular and orbital diseases allows us to infer the presence of normovascular, hypervascular, hypovascular and neovascular flow [32].

In several ophthalmopathies such as glaucoma, hypertension and diabetic retinopathy there are significant alterations in the ocular vascular pattern. It is extremely important to identify these changes, since they guide the establishment of therapeutic behaviors [17]. It is increasingly necessary to develop non-invasive, reproducible and accessible techniques in the study of ocular blood flow [8].

A positive correlation was found between age and biometric measurements of dogs with leishmaniasis (Table 6), inferring that the structures of the ocular bulb follow the growth curve of the animals. It was also observed when the correlation between RI and SPV was correlated with the age of the animals (Table 7), demonstrating that the resistance of the red blood cells to the interior of the external ophthalmic artery increases according to the development of the ocular structures.

\section{CONCLUSION}

The B-mode and Doppler ultrasound examination can be considered important diagnostic tools in the anatomical and vascular study of the ocular bulb of dogs with canine visceral leishmaniasis, allowing the anatomical and biometric evaluation of the ocular components, identification of ophthalmopathies and analysis of the vascular behavior of the external ophthalmic artery. Nevertheless, these data can be used as reference values for dogs with this pathology, since it allowed the correlation with healthy animals.

\section{MANUFACTURER}

${ }^{1}$ Mindray Bio-Medical Electronics Co. Ltd. Shenzhen, China.

Ethical approval. The protocols used in this research were approved by the Committee for Ethics in Animal Experimentation - CEEA/UFPI (No. 135/16).

Declaration of interest. The authors report no conflicts of interest. The authors alone are responsible for the content of the paper. 


\section{REFERENCES}

1 Bevilacqua P.D., Paixão H. H., Modena C.M. \& Castro M.C.P.S. 2001. Urbanização da leishmaniose visceral em Belo Horizonte. Arquivo Brasileiro de Medicina Veterinária e Zootecnia. 53(1): 1-8. http://dx.doi.org/10.1590/S010209352001000100001.

2 Boroffka S.A.E.B., Voorhout G., Verbruggen A.M. \& Teske E. 2006. Intraobserver and interobserver repeatability of ocular biometric measurements obtained by means of B-mode ultrasonography in dogs. American Journal of Veterinary Research. 67(10): 1743-1749. DOI: 10.2460/ajvr.67.10.1743.

3 Brito F.L.C., Alves L.C., Maia F.C.L., Santos E.S.C., Laus J.L. \& Meunier I.M.J. 2006. Ocular alterations in dogs naturally infected by Leishmania (Leishmania) chagasi. Arquivo Brasileiro de Medicina Veterinária e Zootecnia. 58(5): 768-775. http://dx.doi.org/10.1590/S0102-09352006000500011.

4 Calabrese K.S., Silva L.S., Hardoim D.J., Souza C.S.F. \& Abreu-Silva A.L. 2013. Ocular experimental leishmanisis in C57BL/10 and BALB/c mice induced by Leishmania amazonensis infection. Experimental Parasitology. 133(2): 156-161. DOI: 10.1016/j.exppara.2012.11.008

5 Cottrill N.B., Banks W.J. \& Pechman R.D. 1989. Ultrasonographic and biometric evaluation of the eye and orbit of dogs. American Journal of Veterinary Research. 50(6): 898-903.

6 Dantas-Torres F. 2009. Canine leishmanioses in South America. Parasites \& Vectors. 2(1): 1-8. DOI: 10.1186/17563305-2-S1-S1.

7 Davidson M.G., Nasisse M.P., Rusnak I.M., Corbett W.T. \& English R.V. 1990. Success rates of unilateral vs. bilateral cataract extraction in dogs. Veterinary Surgery. 19(1): 232-236. https://doi.org/10.1111/j.1532-950X.1990. tb01176.x

8 Diniz A.L.D., Moron A.F., Santos M.C. \& Sass N. 2004. Dopplervelocimetria colorida dos vasos orbitais: técnica de exame e anatomia vascular. Radiologia Brasileira. 37(4): 287-290. https://doi.org/10.1590/S0100-39842004000400013

9 Ekesten B. 1994. Biological variability and measurement error variability in ocular biometry in Samoyed dogs. Acta Veteria Scandinavica. 35(4): 427-433.

10 Farah M.E. 2002. Descolamento regmatogênico da retina. In: Lavinsky J. (Ed). Doenças prevalentes da retina e vítreo. Cultura Médica. Rio de Janeiro: Guanabara Koogan, pp.95-134.

11 Feitosa M.M., Ikeda F.A., Luvizotto M.C.R. \& Perri S.H.V. 2000. Aspectos clínicos de cães com leishmaniose visceral no município de Araçatuba - São Paulo (Brasil). Clínica Veterinária. 28(1): 36-44.

12 Fulgêncio G.O., Viana F.A.B. \& Michalick M.S.M. 2004. Alopecia periocular, blefarite, ceratoconjuntivite e uveíte: Manifestações oftálmicas da leishmaniose visceral canina. Revista Universidade Rural: Série Ciências da Vida. 24(1): 31-32.

13 Garcia-Alonso M.M.; Mirón C. \& Molano I. 1998. Patología ocular associada a leishmaniosis canina. Consensus Differential Veterinary. 6(1): 49-53.

14 Garcia-Alonso M.M, Blanco A., Reina D., Serrano F.J., Alonso C. \& Nieto C.G. 1996. Imunopathology of the uveitis in canine leishmaniasis. Parasite Immunology. 18(1): 617-624. https://doi.org/10.1046/j.1365-3024.1996.d01-39.x

15 Gellat-Nicholson K.J., Gellat K.N., MacKay E., Brooks D.E. \& Newell S.M. 1999. Doppler imaging of the ophthalmic vasculature of the normal dog: blood velocity measurements and reproducibility. Veterinary Ophthalmology. 2(2): 87-96. DOI: 10.1046/j.1463-5224.1999.00062.x.

16 Gonçalves G.F., Pippi N.L., Raiser A.G., Mazzanti A., Oliveira S.T., Neves J.P., Leotte A.M. \& Hintz C.W. 2000. Biometria ultra-sonográfica bidimensional em tempo real do globo ocular de cães. Ciência Rural. 30(3): 417-420. https://doi.org/10.1590/S0103-84782000000300007

17 Gonçalves G.F., Pippi N.L., Leme M.C., Custódio A.P., Fachin L., Lago E., Silva A.V. \& Pachaly J.R. 2005. Fluxometria Eco-Power-Doppler da artéria oftálmica externa em gatos (Felis catus, LINNAEUS, 1758). Arquivos de Ciências Veterinárias e Zoologia. 8(2): 117-124.

18 Hijar M.V. 2008. Oftalmologia dos animais de companhia. Ultrassonografia Ocular. 3(1) 462.

19 Koutinas A.F., Polizopoulou Z.S., Saridomichelakis M. N., Argyriadis D., Fytianou A. \& Plevraki K.G. 1999. Clinical considerations on canine visceral leishmaniasis in Greece: a restrospective study of 158 cases (1989-1996). Jounal of American Animal Hospital Association. 35(5): 376-383. DOI: 10.5326/15473317-35-5-376.

20 Kurtz D., Manny R. \& Hussein M. 2005. Variability of the ocular component measurements in children using A-scan ultrasonography. Optometry anda Vision Sience. 8(1): 35-43. DOI: 10.1097/00006324-200401000-00008. 
21 Laus J.S., Canola J.C., Mamede F.V., Almeida D.E., Godoy G.S., Oliveira C.J.B. Pontin K., Albuquerque S. \& Alessi A.C. 2003. Orbital cellulites associated with Toxocara canis in a dog. Veterinary Ophthalmology. 6(4): 333-336.

22 Miller P.E. \& Murphy C.J. 1995. Visionin Dogs. Journal of American Veterinary Medical Association. 207(12): 1623-1634.

23 Missawa N.A. \& Lima G.B.M. 2006. Distribuição espacial de Lutzomyia longipalpis (Lutz \& Neiva, 1912) e Lutzomyia cruzi (Mangabeira, 1938) no Estado de Mato Grosso. Revista da Sociedade Brasilera de Medicina Tropical. 39(4): 337-340. http://dx.doi.org/10.1590/S0037-86822006000400004

24 Molleda J.M., Novales M. \& Ginel P.J. 1993. Clinical and histopathological study of the eye in canine leishmaniasis. Israel Journal of Veterinary Medicine. 48(1): 173-178.

25 Naranjo C. Fondevila D., Leiva M., Roura X. \& Peña T. 2005. Caracterization of lacrimal gland lesions and possible pathogenic mechanisms of keratoconjunctivitis sicca in dogs with leishmaniosis. Veterinary Parasitology. 133(1): 37-47.

26 Novellas R., Espada Y. \& Gopegui R.R. 2007. Doppler ultrasonographic estimation of renal and ocular resistive and pulsatility indices in normal dogs and cats. Veterinary Radiology and Ultrasound. 48(1): 69-73. DOI: 10.1111/j.17408261.2007.00206.x.

27 Oliveira C.L., Assunção R.M., Reis I.A. \& Proietti F.A. 2001. Spacial distribution of human and canine visceral leishmaniasis in Belo Horizonte, Minas Gerais State, Brazil, 1994-1997. Cadernos de Saúde Pública. 17(5): 1231-1239. http://dx.doi.org/10.1590/S0102-311X2001000500023

28 Paunksnis A., Svaldeniene E., Paunksniene M. \& Babrauskiene V. 2001. Ultrasonographic evaluation on the eye parameters in dogs of different age. Ultragarsas. 39(2): 48-51. DOI: 10.2460/ajvr.67.10.1743.

29 Peña M.T., Roura X. \& Davidson M.G. 2000. Ocular and periocular manifestations of leishmaniasis in dog: 105 cases (1993-1998). Veterinary Ophthalmology. 3(1): 35-41. DOI: 10.1046/j.1463-5224.2000.00106.x

30 Peña M.T., Naranjo C., Klauss G., Fondevila D., Leiva M., Roura X., Davidson M.G. \& Dubielzig R.R. 2008. Histopathological features of ocular Leishmaniosis in the dog. Journal of Comparative Pathology. 138(1): 32-39. DOI: 10.1016/j.jcpa.2007.09.004

31 Romero G.A.S. \& Boelaert M. 2010. Control of visceral leishmaniasis in Latin America - A stematic review. PLoS Neglected Tropical Disease. 4(1): 584. https://doi.org/10.1371/journal.pntd.0000584

32 Schmid V. \& Murisier N. 1996. Color Doppler imagining of the orbit in the dog. Veterinary \& Comparative Ophthalmology. 6(1): 35-44.

33 Serra E.G. \& Brunelli A.T.J. 2005. Avaliação ultra-sonográfica da lente no desenvolvimento da catarata. Revista Nosso Clínico. 8(1): 1-6.

34 Singh R.P. \& Young L.H. 2006. Diagnostic tests for posterior segment inflammation. International Ophthalmology Clinics. 46(2): 195-208. DOI: 10.1097/00004397-200604620-00016.

35 Slappendel R.J. 1988. Canine leishmaniasis. A review based on 95 cases in The Netherlands. The Veterinary Quartely. 10(1): 1-16. DOI: 10.1080/01652176.1988.9694140.

36 Viega C.C.P., Bomfim P.C., Oliveira P.C., Souza B.G., Ferreira A.M.R., Oliveira G.F. \& Ligeiro L.R. 2012. Uso da ultrassonografia em modo-B e do Power Doppler no diagnóstico do descolamento da retina em um cão - relato de caso. Revista Brasileira de Medicina Veterinária. 34(4): 349-352. 